\title{
BUDGETARY PROJECTION IN THE SYSTEM OF FINANCIAL AND ECONOMIC REGULATION OF SOCIAL PROCESSES*
}

\author{
Igor Chugunov', Valentina Makohon²
}

\begin{abstract}
The purpose of the article is to reveal the role of budgetary projection in the system of financial and economic regulation of social processes within the framework of improving the efficiency of fiscal policy intended to macroeconomic stability maintenance in both countries with transformational and advanced economies. The comparative and factorial methods allowed to developthe features of the institutional environment of the budgetary progection methodology, to identify approaches for its improvement. Methodology. Substantiation of the role of budget forecasting in the system of financial and economic regulation of social processes, determination of provisions for improving its methodology is based on generalized and systematic approaches that are applied in both developed and transformational economies. An analysis of the stages of the process and the budgetary projection methods evaluation, that are used in different countries, have been carried out. Results showed that the efficient budgetary projection methodology is the basis for sound fiscal policy. The development of realistic budgetary projections facilitates justified management decisions aimed at ensuring the country financial firmness. Devia-tions from budget revenues from the projected indicators do not make it possible to achieve certain fiscal policy outcomes and, accordingly, cause a budget cut. In order to develop realistic budgetary projections, a welldesigned and coherent database is needed for all time series, necessary to analyze and project budget revenues. Time series of key determinants affecting the budget revenues level should be available at different frequencies (monthly, quarterly, annually). Where data reflecting similar economic processes by different revenue sources are available, any differences between them shall be determined by reference to their coverage and methodology. Practical implications. Budgetary projections are the basis for the formation of effective fiscal policy and the benchmark of the reproduction process. Adequate level of justification for budget projection will help to provide a dynamic balance of budgetary indicators and the budgetary system stability. Institutional changes to the budgetary projection methodology should be made on the basis of taking into account the dynamic interrelation of budgetary and macroeconomic indicators. The remarkable task here is the development of an economic and mathematical model based on the assessment of the national economy capabilities by reference to the assessment of macroeconomic proportions and the corresponding social and economic conditions of social production. Value/ originality. Developing the budgetary projection approaches in the context of improvement of the fiscal policy efficiency is an important precondition for ensuring macroeconomic stability. In order to increase the budget projection justifiability, it is advisable to make institutional changes to its methodology. Based on the methioned above, the article reveals the essence and role of the budgetary projection in the system of financial and economic regulation of social processes in the context of improving the fiscal policy effectiveness aimed at macroeconomic stability maintenance; approaches to improving the budgetary projection methodology have been identified, and it has been determined that the soundness and feasibility of budgetary projection are the basis for effective fiscal policy. The predictability of budgetary criteria, budgetary architectonics contribute to improving the efficiency of transformations in the public finance system.
\end{abstract}

Key words: budget, budgetary projection, fiscal policy, budgetary system, budgetary architectonics.

JEL Classification: E62, H60, H68

\footnotetext{
Corresponding author:

${ }^{1}$ Kyiv National University of Trade and Economics, Ukraine.

E-mail: chugunov055@gmail.com

ORCID: http://orcid.org/0000-0003-4915-1267

${ }^{2}$ Kyiv National University of Trade and Economics, Ukraine.

E-mail: makvknteu@gmail.com

ORCID: http://orcid.org/0000-0002-2331-8455
}

\footnotetext{
* The article is prepared on the basis of the scientific research work "Financial and budgetary strategy of economic growth" (number of state registration of work 0119U100577).
} 


\section{Introduction}

The development of social relations has led to the creation of new social and economic conditions intended to the effective organization of the public finance management system and its components on the basis of sound and feasible financial and budgetary projections, which take into account both economic and political priorities, that makes it possible to ensure budgetary balance, integrated reciprocity of the state governance measures for social and economic processes in the short-, medium- and long-term.

Budgetary projection indicators, acting as benchmarks for fiscal policy making, determine to a certain extent the national economy functioning conditions and the living standards. Since budgetary expenditures and their sources of funding are mutually agreed in the process of budgetary projections design, the possibilities of the public administration bodies to perform their functions are determined and the level of tax burden is justified. Therefore, the enhancement of the budgetary projection methodology, improvement of scientific justification and feasibility of the projection indicators are a precondition to ensure the effective social and economic development of the country.

Developing the efficient projection models based on institutional changes in the financial and economic environment will permit to respond to the endogenous and exogenous factors impact, while preserving the parameters of holistic development of the budgetary system and budgetary balance in the context of economic transformations. The mentioned above indicates the relevance and timeliness of this study. Thus, the problem of the study is as following: what is the role of the budgetary ptojection in the system of financial and economic regulation of social processes, what course of the budgetary projection methodology changes will ameliorate the level of the budgetary parameters feasibility and the dynamic balance of the budgetary system accordingly? This article aims to expose the role of budgetary projection in the system of financial and economic regulation of public processes in the context of improving the fiscal policy efficiency, to summarize and justify the approaches to improve the budgetary projection methodology.

\section{Approaches to the essence and role of the budgetary projection in the system of financial and economic regulation of social processes}

Projection is a method that uses both past experience and current assumptions about the future to determine it (Heyets, 2008); the process of obtaining scientifically justified probabilistic assessments of possible ways and outcomes of the system development, as well as the resources and organizational measures required for this purpose (Encyclopedic Dictionary of Public Administration, 2010); scientifically justified forecast on directions of the country development, separate branches of economy or separate administrative divisions, possible state of economy and social sphere in the future, as well as alternative ways and terms of achievement of economic and social development parameters (Law "On State Forecasting and Development of Programs of Economic and Social Development of Ukraine"); system of scientifically justified notions of course, criteria, principles, goals and priorities of the social and economic development of the country for the relevant period, indicating the main projected indicators, benchmarks and measures to ensure their achievement (Law "On State Forecasting and Programs of Socio-Economic Development of the Republic of Belarus", 1998).

Thus, the forecasting process determines the level of influence of exogenous and endogenous factors, possible contradictions and disproportions, as well as assesses trends and vectors of the object of forecasting. Accordingly, forecasting is the basis for making sound planning decisions, generating vectors of probable development of the forecasting object on the basis of possible directions of state regulation of socio-economic processes.

The essence of the budget projection is: to develop the main indicators of the state budget for the future, projection of the most important budget revenues and expenditures (Klets, 2007); the real calculations, assumptions about the budget development course, possible states of its income and expenses in the future, ways and terms of reaching these states (Financial and Credit Encyclopedic Dictionary, 2004).

In scientific research it is hypothesized that the budgetary projection level depends on political, institutional and economic determinants (Boukari, JoséVeiga, 2018). Therefore, raising the justification level of the budgetary projection comprises an assessment of possible changes in the relevant determinants.

The importance of the budgetary projection developing is reflected in the strategic documents of socio-economic development of the countries. In particular, it is determined that a sound income policy aimed at achieving and maintaining their maximum consideration amount should meet a number of criteria: ensuring predictability and stability; long-term vision, i.e. a five-year forecast horizon is the least acceptable; systematic i.e. the regulation of any institutional entity kind of income should be accompanied by an assessment of the consequences of this decision for all other entities and the economy as a whole; ensuring effective monitoring and projection of risks associated with the state-owned enterprises activities, since their financial results determine the probability of these threats and the amount of additional debt pressure on the budget (On Internal and External Situation of Ukraine in 2017).

The annual socio-economic development projection is the starting basis for drafting republican and local 
budgets and for developing major areas of monetary and exchange policy. Herewith, several scenarios of projection are developed taking into account different influence trajectories of internal and external political, socio-economic and other factors (On State Forecasting and Programs of Socio-Economic Development of the Republic of Belarus, Law dated May 05, 1998, No. 157-3.).

Under the Stability and Development Pact (Nicolae, 2013), the European Union countries are required to develop long-range budget plans containing the profection indicators of revenue sources. In accordance with European Community's Council Directive (2011/85/EU, 2011), the countries of the European Union define a medium-term budgetary framework that includes prospective estimates based on the assumption that fiscal policy will remain unchanged.

\section{Basic principles for developing budgetary projection models}

The budgetary projection process in both advanced and transformational economies consists of several stages, in particular: monitoring and analysis of data; the collection of basic data required for projection, including the forecast development of the approximate values of the original tax base and components of the macroeconomic projection; forming fiscal policy and economic assumptions for the projection periods; projection and its evaluation process, including the development or improvement of projection models, the collection of expert evaluations, the combination of alternative forecasts, the projection evaluation; internal adjustment of the projection results combined with assessment of the fiscal policy changes impact; refinement of the projection on the basis of internal adjustment; publication of a report on estimated budget revenues.

At the same time, there is a considerable range of budgetary projection methods used in both advanced and transformational economies. In particular, according to "Manual on Fiscal Transparency, 2007", the following basic budgeting methods include: effective tax rates; projection models using macroeconomic variables, including flexibility to macroeconomic indicators, autoregressivemoving-average models, vector autoregression, drawback mainyenance vector model, Holt-Winters exponential smoothing; microimitation models.

When applying the effective tax method, the forecast for each tax is made by multiplying the tax base forecast by the corresponding effective tax rate:

Level of $\operatorname{tax}$ revenues $\beta=$

Effective tax rate $\beta{ }^{*}$ Proxy Tax Base $\beta$,

where $\beta$ means the projection value of the relevant indicator,

Effective tax rate,

Proxy Tax Base means a data series equal in value or close to the relevant tax base.
The effective tax rate is calculated by dividing the revenue amount from a particular tax for the previous period by the estimated tax base or its approximate value:

Effective tax rate $\dot{t}=$ Level of tax revenues $\dot{\mathfrak{t}} /$ Proxy Tax Base $\dot{t}$

Thus, the calculation of the potential tax base for each tax leads to an effective assessment of the legislation on tax objects. However, the same economic assumptions are required for all tax base forecasts, and any changes to the tax base due to policy changes should be made separately.

Projection by models using macroeconomic variables is widely used to project the budget revenues. The following methods are based on the interrelations between the certain microeconomic variables dynamic, notably the feasible GDP and the budget revenues rate of growth. There is a trade-off between the complexity of the model and the quality of the forecast. There may be situations where the use of simple models provides accurate projections and requires less effort based on the level of resources and time involved. More sophisticated general equilibrium models allow us to assess the dynamic linkages between fiscal variables and macroeconomic parameters, as well as to assess the impact of changes in fiscal policy, but developing such models requires stable structural linkages in the economy, substantial data volumes, and effortless application. of these methods in countries with transformational economies.

Micro-simulation models are based on modeling tax revenue for typical taxpayers or their operations. Accordingly, the use of these models implies the availability of microlevel data on tax revenues and features of economic activity of taxpayers, consolidated material balance. This method requires significant amounts of time and data, but can be effective in calculating the impact of tax changes on the level of budget revenues and assessing the distributional effects of changes in fiscal policy.

At the same time, the most efficient budgetary projection methodology is deemed to be the combination of different projection methods, that ameliorates the projection accuracy level. Accordingly, with a high level of uncertainty about the future situation, it is advisable to combine forecasting methods, using different weighting coefficients obtained from different models. The combination is well-handed by averaging, whether there are no remarkable evidences of one method is more effective than others.

It is important to note that at this stage of social development, in many countries, medium- and longterm budgetary planning is in place, which accordingly involves the development of medium- and long-term projections that can capture the long-term interrelations between budget revenues and the factors of their determination. 
At the same time, the continuation of the time horizon of budget projection changes its content and role in the system of financial and economic regulation of social processes. For instance, the short-term forecasts are developed for the term up to one year and do not contain the fiscal and planning features. The previous budget revenue indicators are used to develop the one-dimensional autoregressive models, is there are the time series of high frequency data, particularly, at least 50 oversights. Due to moderate data requirements (mostly only tax revenue data are needed) and high accuracy of short-term forecasting, ARIMA, VAR and other models, based on an estimate of general trends in a particular industry, are used to forecast budget revenues in both advanced and transformational economies.

Developed by modeling the future public revenues and expenditures under the demographic, macroeconomic and other predications, the long-term projections are the tools for influence on the public relations evolution. On this basis, the principles of public administration are justified to ensure macroeconomic stability and sustainable economic development. At the same time, long-term projections are based on the assumption that there is a strong link between tax revenues and the potential tax base. According to the forecasting methodology, the regression of time series in many countries is performed respectively to the certain tax base or its approximation and the other variables that are considered to affect the final revenue indicators (including slack variables for tax changes, complience of the tax legislation, number of taxpayers, seasonal factors, etc.). If there are constraints imposed by the data obtained, a number of macroeconomic indicators, in particular GDP, can be used as a tax base. If the model is directly proportional and the tax base is adjusted according to changes in the taxation regulations over time, an assessment of tax elasticity is made, it can be used to calculate tax revenue growth in the next period then, when the tax mechanism is stable. Also, when developing long-term budgetary projections, considerable attention is paid to taking into account economic cyclicality by calculating the structural balance.

\section{Approaches to budget revenues projections in Ukraine}

The simulation objects in budgetary projection in Ukraine are mainly budget-forming taxes: value added tax (the share in the consolidated budget revenue for $2009-2018$ is $30.17 \%$ ); personal income tax (the share in the consolidated budget revenue for 20092018 is $16.64 \%$ ); corporate income tax (the share in the consolidated budget revenue for $2009-2018$ is $10.24 \%$ ).

The main factors that are taken into account when projecting value added tax revenues are: dynamics of growth of retail trade turnover of enterprises and export of goods; changes in conjuction of the gross added value in economic activities; volume of services realization; the level of gross capital formation. The peculiarity of the projection model of value added tax is: in determination of the estimated tax base on the indicators of socio-economic development of the country and the real tax rate; taking into account the estimation of value added tax on goods (works, services) produced in Ukraine, including the budgetary compensation of the impact of the dynamics of goods export and the average annual exchange rate of hryvnia to the US dollar on the budgetary compensation of the tax and the impact of dynamics and changes in the situation of domestic tax demand. At the same time, improving the administration efficiency of this tax and its forecast model determines the necessarity to create a mechanism that will ensure its recompence.

The development of the value added tax projection is based on the determination of the estimated tax base of this tax and the real tax rate:

$V A T t=T B t * \mathrm{ER} t / 100$,

where, $V A T t$ is the value added tax revenues projection;

TBt is the tax base;

$\mathrm{ER} t$ is the effective tax rate;

$t$ is the time period index.

The effective tax rate reflects the actualtax level that has evolved with respect to the tax base:

$$
\mathrm{ER} t-1=(V A T t-1 / T B t-1) * 100
$$

The projection model of personal income tax includes projections of income from this tax for all types of income: employees; individuals engaged in independent professional activity; fixed tax and other types of income reduced by the amount of tax on personal income from tax rebate:

$$
P I T=P I T R D+P I T I P A F T+P I T O I-P I T T R,
$$

where $P I T R D$ is the income tax on employees;

PIT IPAFT is the income tax from on individuals engaged in independent professional activity, the fixed tax;

PITOI is the tax from other types of income;

PITTR is the estimated amount of tax refund from the tax rebate received by the payers.

In the process of projection of the personal income tax, the following are taken into account: the dynamics of the wage costs growth; dynamics of income growth in connection with the increase of the social protection floor; increase in mixed household incomes due to intensification of individual entrepreneurial activity; legalization of payment of wages; raising the subsistence level and minimum wage.

The main factors that affect the corporate tax income include: the dynamics of income tax, the financial result of enterprises before tax; tax reporting indicators 
according to the consolidated income tax return for the preprojection period; performance indicators for the administration of income tax; income of profitable enterprises in previous periods.

Development of the corporate income tax projection is based on the definition of: the tax object of the corporate income tax:

$$
T O=I-F C-O E,
$$

where $T O$ is the tax object;

$I$ is the income included when calculating the tax object;

$F C$ is the flat cost of goods sold, works performed, services provided;

$O E$ is the other costs.

Insufficient quality levels and relatively short time series of macroeconomic and budgetary data in Ukraine, combined with unstable economic and political situation, complicate the development of structurally complex, dynamic budgetary projection models. Limited technical capabilities narrow down the range of methods that can be applied in budgetary projection.

Thus, the use of simple multidimensional models on a macroeconomic basis, where tax revenues are expressed as a function of the tax base approximate value the and additional instrumental variables that take into account seasonal changes, the general trend in the industry, economic and political disruptions, as well as one-dimensional models of ARIMA are a good starting point to review a limited amount of data.

\section{Areas for improvement of the budgetary projection methodology}

The process of budget revenues projection should be based on clear organizational principles to obtain reliable projections, regardless of political interference. Although it is difficult to obtain high-precision income projections in countries with a transformational economy, given the high macroeconomic volatility, low reliability of economic data of tax series and a large number of changes to the tax regime in a relatively short period of time, it is important to introduce a reliable and transparent forecasting system, equipped with specialized and qualified staff, relevant databases and up-to-date software, as well as internal and external mechanism a list of revenue estimates.

In transformational economies, as the technical base develops and the volume of data grows, the range of forecasting methods can be extended to more complex models. Intel alia, VAR, VECM and micro-simulation models. The use of these models can provide a qualitative analysis of the impact of changes in the tax regime on future revenues, but there are significant limitations to the development of such models in transformational economies, ranging from the cost of resources (the need for comprehensive data, time expenditures) to legal restrictions on the handling of confidential information of the taxpayer and insufficient compliance with tax law and incompleteness of information on the taxpayers activities. However, the micro-simulation approach as a tool for tax revenues projection from the large key enterprises may be used in the future.

Gathering sets of reliable data with the right level of disaggregation is a necessary step in budget revenues projection. At the same time, the quality of certain model-based projections is highly dependent on the quality and volume of the initial data. It is also important to collect information on all possible determinants of budget revenues, including reliable data on the tax base approximate values and major macroeconomic variables, quantitative estimates of changes in the tax regime, the impact of economic shocks that can help build sound projection models.

The budgetary projection should be based on an official macroeconomic projection developed by the relevant government bodies. Taking the official macroeconomic projection parameters as the initial data for development the revenue projections, devided on different revenue sources. Involving different government agencies in the projection process requires effective coordination between them to achieve a holistic macroeconomic vision, which will be used as information for projection revenues. The absence of a statutory procedure and algorithm for the revenue projection process makes the current projection process non-trnsparent and vulnerable to political interference.

Considering the peculiarities of the development of public relations, a significant task is the legislative consolidation of rules on the use of external expertise in the process of budget revenues projection, which will improve the accuracy of the validity of the projection based on a critical assessment of the main assumptions and sources of information used to make budgetary projection.

\section{Conclusions}

An effective budgetary forecasting methodology is the basis for sound fiscal policy-making. The development of realistic budgetary projections facilitates justified management decisions aimed at ensuring the fiscal balance and country financial firmness at a whole. Deviations of budget revenues from the projected indicators do not make it possible to achieve certain fiscal policy outcomes and, accordingly, cause a budget cut. In order to develop more accurate budgetary projections, a detailed analysis of the country's financial and economic environment is required to identify regular trends in the dynamics of macroeconomic indicators. Time series of key determinants affecting the budget revenues level should be available at different frequencies (monthly, quarterly, annually). 
Where data reflecting similar economic processes by different revenue sources are available, any differences between them shall be determined by reference to their coverage and methodology. Institutional changes to the budgetary projection methodology should be made on the basis of taking into account the dynamic interrelation of budgetary and macroeconomic indicators. The remarkable task here is the development of an economic and mathematical model based on the assessment of the national economy capabilities by reference to the assessment of macroeconomic proportions and the corresponding social and economic conditions of social production.
At this stage of social development, issues of improvement are gaining importance in developed and transformational economies, full implementation of medium-term budgetary planning and projection in the budget process is based on macroeconomic strategies. The level of validity and feasibility of the projected budgetary indicators depends on the degree of coherence of the political and economic component. The importance of further research on these issues is due to the expediency of improving the budgetary projection methodology based on the development of approaches that will take into account both the cyclicality and the dynamics of economic processes.

\section{References:}

Heyets, V. M. (2008). Modeli i metody socialno-economichnoho prohnozuvannia [Models and methods of socioeconomic planning]. Kharkiv: PH "INZHEK", 396 p.

Surmin, Yu. P., Bakumenko, V. D., Mihnenko, A. M. and etc. (2010). Entsyklopedychnyi slovnyk z derzhavnoho upravlinnia [Encyclopedic Dictionary of Public Administration]. Kyiv: NADU, 820 p.

Pro derzhavne prohnozuvannia ta rozroblennia prohram ekonomichnoho i sotsialnoho rozvytku Ukrainy [On State Forecasting and Development of Programs of Economic and Social Development of Ukraine]. Law of Ukraine dated 03.03.2000 No. 1602-III.

O gosudarstvennom prognozirovanii i programmah sotsyalno-ekonomicheskogo razvitiia Respubliki Belarus [On State Forecasting and Programs of Socio-Economic Development of the Republic of Belarus]. The Law of the Republic of Belarus dated May 5, 1998 No. 157-3.

Klets, L. (2007). Biudzhetnyi menedzhment [Budget Management]. Center for Educational Literature, 640 p.

Gryaznova, A. G. (ed.) (2007). Finansovo-creditnyi encyclopedicheskiy slovar [Financial and Credit Encyclopedic Dictionary]. Moscow: Finance and Statistics, 1165 p.

Boukari, M., \& José Veiga, F. (2018). Disentangling political and institutional determinants of budget forecast errors: A comparative approach Journal of Comparative Economics, Volume 46, Issue 4, pp. 1030-1045.

Pro vnutrishnie i zovnishnie stanovyshche Ukrainy na 2017 rik [On Internal and External Situation of Ukraine in 2017]. Message from the President of Ukraine to the Verkhovna Rada of Ukraine. Retrieved from https://zakon. rada.gov.ua

Nicolae, P. V. (2013). The Financial and Budgetary Discipline in Romania - The Arrears of Local Public Authorities. Annals - Economy Series, vol. 2, pp. 221-226.

Council Directive 2011/85 / EU of 8 November 2011 on requirements for budgetary frameworks of the Member States (2011). Official Journal. L 306. 41-47.

Manual on Fiscal Transparency (2007). International Monetary Fund. Retrieved from: https://www.imf.org/ external/np/pp/2007/eng/051507m.pdf 